\title{
An Analysis of E-Content Modules of Indian OERs: A Case Study of E-Pg Pathshala
}

\author{
Subhajit Panda ${ }^{1}$ \\ ${ }^{1}$ Assistant Librarian, Chandigarh University, Mohali, Punjab, India. \\ Correspondence E-mail Id: editor@eurekajournals.com
}

\begin{abstract}
OER is a distinct way of learning in the modern era, without any geographical barriers and money. There are two types of OER depending on how it approaches its user, Open Course Ware (OCW) and MOOCs. In India, e-PG Pathshala is such an innovation maintained by UGCINFLIBNET and funded by MHRD. As part of its National Education Mission through ICT (NME-ICT), it is a wide e-learning platform in terms of its subject material and breadth of use as well. In this context, the present study is an attempt to assess the status of e-content modules of e-PG Pathshala in the different subject discipline. The findings of the study identified that among the two broad subject category, AHSS field occupied $62 \%$ of total uploaded modules and rest $38 \%$ covered by STEMM. In consecutive divisions of the subject field into five major subject discipline reveals that "Social Sciences" and "Arts, Humanities and Languages" contribute double concerning e-content modules than "Engineering, Technology and Management", "Physical and Basic Sciences" and "Bio-Medical and Health Sciences". Additional statistical analysis (Pearson's Correlation test) shows that a strong positive correlation was observed between the two variables No. of Paper \& No. of Uploaded Module ( $\mathrm{rp}=0.683, \mathrm{p}=<.001$ ).
\end{abstract}

Keywords: OER, OCW, MOOCs, e-PG Pathshala, e-Content Modules, e-Learning.

\section{Introduction}

With the advancement of information and communication technology (ICT), the process of teaching and learning has undergone a tremendous change. The tendency towards the learning through self directed educational resources in various fields has automatically grown. Self-Directed Learning process is described as a learners inherent ability to manage his or her own learning process, by understanding himself/herself as the source of his/her own decisions and actions feeling it as a responsibility towards his/her own lifelong learning (Sze-yeng \& Hussain 2010). Open Educational Resources (OERs) prove themselves as an essential platform for enhancing self-learning by providing study material, course note, interactive videos for 
learning purpose and free of cost by reputed institutions and academicians. Among the few recognized OER, e-PG Pathshala has a wide influence in the growth, promotion and advancement of e-learning in India. It is an e-learning platform maintained by INFLIBNET Centre with the support of University Grants Commission and funded by MHRD Government of India. It acts as a gateway for all courses at post graduate level. In e-PG Pathshala for development of e-content in almost 70 subjects at postgraduate level with High quality, curriculum-based, interactive content in different subjects across all disciplines of social sciences, arts, fine arts and humanities, natural and mathematical sciences, linguistics and languages. The present study try to analyze the status of e-content modules and constitute papers in e-PG Pathshala.

\section{Review of literature}

OER, Open Course Ware (OCW) or Massive Open Online Courses (MOOCs) in association with e-learning is not a new dimension of research, although there present a huge lack of awareness about Indian OER platform like e-PG Pathshala. Some potential study which tries to present the picture of the status of Indian OER and e-learning platform about e-PG Pathshala are discussed below:

In her paper "A Study on the Role of e-PG Pathshala in the Development of E-Learning" Maharaj (2018) deals with the meaning of e-Learning, the aims and benefits of e-PG Pathshala and its statistical use of data in different fields. The study further covers the ratio of the total number of visitors and registered visitors; state wise visitors in India regarding total state population and total higher education enrollment; and subject wise uploaded modules with respective visitors.

Hajam (2016) presented a SWOT Analysis of e-learning platform e-PG Pathshala. The paper discussed about the concept of open course ware in general and elaborated in particular on meaning, purpose and objective of e-PG Pathshala in India to evaluate the SWOT (Strength, Weakness, Opportunity and Threat) Analysis of e-PG Pathshala. Additionally the study covered the role of Libraries and Information Centers in delivery of information electronically had also been specified.

Our present research is a further extension of the preceding works, seeking to determine the status of e-content module within different subject discipline in e-PG Pathshala.

\section{Objectives of the Study}

1. To examine the present status of e-Content in Indian OER e-PG Pathshala.

2. To analyze the subject wise contribution to e-content in e-PG pathshala.

3. To explore the contribution of e-content in more depth sub-category level.

4. To determine the statistical correlation present between number of papers and uploaded modules in different subject discipline. 


\section{Scope of the Study}

The scope of the study extends to all 67 subject categories (actual no=70, but the data of three field missing from e-PG Stats) of e-PG Pathshala which primarily divided into two broad categories i.e. STEMM (Science, Technology, Engineering, Medical \& Management) and AHSS (Arts, Humanities \& Social Sciences), which further sub-divided into 6 major subject categories. Additionally the study tests the existence of the statistical tests to examine the presence of any correlation between the papers and modules count. The following table 1 represents the total coverage of e-PG Pathshala according to occupied e-contents (e-PG Pathshala, n.d.-a).

Table 1.e-Contents in e-PG Pathshala

\begin{tabular}{|l|l|l|l|l|}
\hline e-Text & Video & Experts & Quiz & Subjects/ Papers \\
\hline $20000+$ & $19000+$ & $3200+$ & $30000+$ & $70 / 723$ \\
\hline
\end{tabular}

\section{Research Methodology}

Data for the study were collected during May 2020 from the website of e-PG Pathshala (http://epgp.inflibnet.ac.in/) (e-PG Pathshala, n.d.-b). Through data mining was done from the raw data with the use of spreadsheet software for enhanced visualization. The study was categorized systematically from broad to narrow category of subject field covered under e-PG Pathshala. At first the data was arranged according to two broad category, AHSS and STEMM followed by 5 major subject discipline, such as Social Sciences; Arts, Humanities and Languages; Engineering, Technology and Management; Physical and Basic Sciences; and Bio-Medical and Health Sciences; and 67 major subject sub-categories in subsequent steps. The major subjects subcategory contributed 908 papers and 25174 modules. To understand the arrangement and correlation between different variables of the dataset, Pearson Correlation test was done using statistical software JASP (v. 0.12.0.0).

\section{Data Analysis}

After the data collection is over, the raw data now analysed by simple quantitative method basically in form of a percentage of the total, based on a set of relevant parameters suitable for interpreting the present study.

\section{(A) Contribution of Broad Branches of Subject}

Table 2 depicts that though the AHSS branch covered only two major subject categories, it occupied 62\% (=15544) of total modules uploaded in e-PG Pathshala. The STEMM branch of the subject covered $38 \%$ of uploaded modules with 3 major subject categories. Again, the subject field AHSS also suppressed the STEMM field considering the no. of sub-categories and no. of paper. 
Table 2.Contribution of Broad Branches of Subject

\begin{tabular}{|l|l|l|l|l|l|l|}
\hline $\begin{array}{l}\text { S. } \\
\text { N. }\end{array}$ & $\begin{array}{l}\text { Branch } \\
\text { of } \\
\text { Subjects }\end{array}$ & $\begin{array}{l}\text { No. of Major } \\
\text { Subject } \\
\text { Category }\end{array}$ & $\begin{array}{l}\text { No. of } \\
\text { Sub-Categories }\end{array}$ & $\begin{array}{l}\text { Total no of } \\
\text { Papers }\end{array}$ & $\begin{array}{l}\text { Total no of } \\
\text { uploaded } \\
\text { modules }\end{array}$ & $\begin{array}{l}\text { Percentage } \\
(\%)\end{array}$ \\
\hline $\mathbf{1}$ & AHSS & 2 & 38 & 537 & 15544 & 62 \\
\hline $\mathbf{2}$ & STEMM & 3 & 29 & 371 & 9630 & 38 \\
\hline \multicolumn{2}{l}{ Total } & 5 & 67 & 908 & 25174 & 100 \\
\hline
\end{tabular}

\section{(B) Contribution of Major Subject Category}

Its is found from table 3 that among the 5 major subject category, "Social Sciences" contributed the maximum number of modules [8782(35\%)] in e-PG Pathshala followed by "Arts, Humanities and Languages" and "Engineering, Technology and Management" with $6762(27 \%) \& 3658(54 \%)$ modules respectively. It is interesting to note that among the first three contributors of e-PG Pathshala two are of AHSS field and one STEMM field of subject category.

Table 3.Contribution of Major Subject Categories

\begin{tabular}{|l|l|l|l|l|l|}
\hline SN & $\begin{array}{l}\text { Major Subject } \\
\text { Category }\end{array}$ & $\begin{array}{l}\text { No. of } \\
\text { Sub-Categories }\end{array}$ & $\begin{array}{l}\text { Total no } \\
\text { of Papers }\end{array}$ & $\begin{array}{l}\text { Total no of } \\
\text { uploaded modules }\end{array}$ & $\begin{array}{l}\text { Percentage } \\
(\%)\end{array}$ \\
\hline 1 & Social Sciences & 22 & 319 & 8782 & 35 \\
\hline 2 & $\begin{array}{l}\text { Arts, Humanities } \\
\text { and Languages }\end{array}$ & 16 & 218 & 6762 & 27 \\
\hline 3 & $\begin{array}{l}\text { Engineering, } \\
\text { Technology and } \\
\text { Management }\end{array}$ & 10 & 131 & 3658 & 15 \\
\hline 4 & $\begin{array}{l}\text { Physical and Basic } \\
\text { Sciences }\end{array}$ & 8 & 112 & 3345 & 13 \\
\hline 5 & $\begin{array}{l}\text { Bio-Medical and } \\
\text { Health Sciences }\end{array}$ & 11 & 128 & 2627 & 10 \\
\hline
\end{tabular}

\section{(C) Contribution of Sub-Categories (Individual Subjects)}

Under 5 major categories of the subject, there are a total of 67 individual subject discipline which contributed the high quality, curriculum-based, interactive e-content coverage of e-PG Pathshala with 25174 modules across all disciplines of social sciences, arts, fine arts and humanities, natural \& mathematical sciences, linguistics, and languages have been developed by the subject experts working in Indian universities and other R \& D institutes across the country. 


\section{(i) Contributions of Social Sciences}

Table 4 indicates that under the major subject category Social Sciences, "Psychology", was contributed with maximum percentage $(7 \%)$ of total uploaded module; followed by "Economics", "Forensic Science", "Anthropology", "Sociology”, "Indian Culture", "Linguistics", "Social Work Education", "Criminology" have contributed 6\% each. In the third position, there are 5 subjects namely, "Commerce", "Law", "Business Economics", "Women Studies/Gender Studies", and "Library and Information Science", each with 5\% contribution to e-PG modules.

Table 4. Contribution of Social Sciences

\begin{tabular}{|l|l|l|l|l|}
\hline SN & Name of the Subject & $\begin{array}{l}\text { Total no of } \\
\text { Papers }\end{array}$ & $\begin{array}{l}\text { Total no of uploaded } \\
\text { modules }\end{array}$ & $\begin{array}{l}\text { Percentage } \\
(\%)\end{array}$ \\
\hline 1 & Psychology & 16 & 599 & 7 \\
\hline 2 & Economics & 15 & 567 & 6 \\
\hline 3 & Forensic Science & 16 & 560 & 6 \\
\hline 4 & Anthropology & 16 & 559 & 6 \\
\hline 5 & Sociology & 15 & 526 & 6 \\
\hline 6 & Indian Culture & 15 & 524 & 6 \\
\hline 7 & Linguistics & 16 & 493 & 6 \\
\hline 8 & Social Work Education & 16 & 487 & 6 \\
\hline 9 & Criminology & 14 & 482 & 6 \\
\hline 10 & Commerce & 16 & 469 & 5 \\
\hline 11 & Law & 16 & 462 & 5 \\
\hline 12 & Business Economics & 16 & 457 & 5 \\
\hline 13 & Women Studies/ Gender Studies & 15 & 431 & 5 \\
\hline 14 & Library and Information Science & 20 & 395 & 5 \\
\hline 15 & Population Studies & 14 & 383 & 4 \\
\hline 16 & Human Rights and Duties & 10 & 364 & 4 \\
\hline 17 & Geography & 16 & 337 & 4 \\
\hline 18 & Political Science & 7 & 222 & 3 \\
\hline 19 & Adult Education & 8 & 190 & 2 \\
\hline 20 & Education & 15 & 106 & 1 \\
\hline 21 & Public Administration & 15 & 102 & $\mathbf{1 0 0}$ \\
\hline 22 & Buddhist Studies & 12 & 67 & $\mathbf{8 7 8 2}$ \\
\hline Total & $\mathbf{3 1 9}$ & & \\
\hline & & & & \\
\hline
\end{tabular}

(ii) Contributions of Arts, Humanities and Languages

Table 5 is evident that in the Arts, Humanities and Languages field, "Home Science" and "Sanskrit (M.A.)" with 10\% (=640 modules) contribution being the top of the list whereas Chinese is the least contributed subject (almost $0 \%$ contribution). Hindi with $9 \%$ contribution 
being the second highest contributor and in the third position, there are 4 subjects namely, "Performing Arts", "Spanish", "English" and "Sanskrit" each with 8\% contribution.

Table 5. Contribution of Arts, Humanities and Languages

\begin{tabular}{|l|l|l|l|l|}
\hline SN & Name of the Subject & $\begin{array}{l}\text { Total no of } \\
\text { Papers }\end{array}$ & $\begin{array}{l}\text { Total no of uploaded } \\
\text { modules }\end{array}$ & $\begin{array}{l}\text { Percentage } \\
(\%)\end{array}$ \\
\hline 1 & Home Science & 16 & 640 & 10 \\
\hline 2 & Sanskrit (M.A) & 16 & 640 & 10 \\
\hline 3 & Hindi & 16 & 592 & 9 \\
\hline 4 & $\begin{array}{l}\text { Performing Arts (Dance/ } \\
\text { Drama/ Theatre) }\end{array}$ & 16 & 560 & 8 \\
\hline 5 & Spanish & 16 & 560 & 8 \\
\hline 6 & English & 16 & 560 & 8 \\
\hline 7 & $\begin{array}{l}\text { Sanskrit (Acharya in } \\
\text { Vyakrana) }\end{array}$ & 16 & 534 & 8 \\
\hline 8 & Visual Arts & 14 & 487 & 7 \\
\hline 9 & Japanese & 16 & 458 & 7 \\
\hline 10 & Russian Studies & 13 & 436 & 6 \\
\hline 11 & $\begin{array}{l}\text { Media and communication } \\
\text { studies }\end{array}$ & 9 & 383 & 6 \\
\hline 12 & Philosophy & 16 & 333 & 5 \\
\hline 13 & Urdu & 11 & 312 & 5 \\
\hline 14 & Architecture & 6 & 164 & 2 \\
\hline 15 & $\begin{array}{l}\text { Comparative Study of } \\
\text { Religions }\end{array}$ & 13 & 77 & 1 \\
\hline 16 & Chinese & 8 & 26 & $\sim 0$ \\
\hline Total & $\mathbf{2 1 8}$ & $\mathbf{6 7 6 2}$ & $\mathbf{1 0 0}$ \\
\hline
\end{tabular}

(iii) Contributions of Engineering, Technology and Management

Following table 6 shows the contribution of Engineering, Technology and Management field to the e-content coverage of e-PG Pathshala. Among the 10 subjects "Hotel \& Tourism Management" contribute the maximum number of modules [639 (18\%)] in this discipline. It is followed by "Computer Science" with 17\% (633 modules) contribution and "Management", and "Human Resource Management" with 16\% (599 Modules) contribution each. 
Table 6. Contribution of Engineering, Technology and Management

\begin{tabular}{|l|l|l|l|l|}
\hline SN & Name of the Subject & $\begin{array}{l}\text { Total no of } \\
\text { Papers }\end{array}$ & $\begin{array}{l}\text { Total no of uploaded } \\
\text { modules }\end{array}$ & $\begin{array}{l}\text { Percentage } \\
(\%)\end{array}$ \\
\hline 1 & Hotel \& Tourism Management & 16 & 639 & 18 \\
\hline 2 & Computer Science & 17 & 633 & 17 \\
\hline 3 & Management & 15 & 599 & 16 \\
\hline 4 & Human Resource Management & 16 & 599 & 16 \\
\hline 5 & Material Science & 16 & 465 & 13 \\
\hline 6 & Information Technology & 16 & 318 & 9 \\
\hline 7 & $\begin{array}{l}\text { Analytical Chemistry/ } \\
\text { Instrumentation }\end{array}$ & 15 & 222 & 6 \\
\hline 8 & Electronic Science & 15 & & 3 \\
\hline 9 & M Plannning & 2 & 117 & 1 \\
\hline 10 & Risk / Disaster Management & 3 & 45 & 1 \\
\hline Total & $\mathbf{1 3 1}$ & $\mathbf{3 6 5 8}$ & $\mathbf{1 0 0}$ \\
\hline
\end{tabular}

(iv) Contributions of Physical and Basic Sciences

Table 7 explains that "Statistics" contribute the maximum percentage (i.e. 18\%) of the total e-content coverage of Physical and Basic Sciences discipline. "Mathematics", "Chemistry", and "Jyotish-ganit" with $17 \%$ contribution occupied the second position followed by Environmental Science with $16 \%$ contribution.

Table 7.Contribution of Physical and Basic Sciences

\begin{tabular}{|l|l|l|l|l|}
\hline SN & Name of the Subject & Total no of Papers & $\begin{array}{l}\text { Total no of uploaded } \\
\text { modules }\end{array}$ & $\begin{array}{l}\text { Percentage } \\
(\boldsymbol{\%})\end{array}$ \\
\hline 1 & Statistics & 16 & 595 & 18 \\
\hline 2 & Mathematics & 16 & 567 & 17 \\
\hline 3 & Chemistry & 16 & 565 & 17 \\
\hline 4 & Jyotish- ganit & 16 & 560 & 17 \\
\hline 5 & Environmental Science & 16 & 530 & 16 \\
\hline 6 & Physics & 12 & 343 & 10 \\
\hline 7 & Geology & 11 & 136 & 4 \\
\hline 8 & Earth Sciences & 9 & 49 & 1 \\
\hline \multicolumn{2}{|l|}{ Total } & $\mathbf{1 1 2}$ & $\mathbf{3 3 4 5}$ & $\mathbf{1 0 0}$ \\
\hline
\end{tabular}

\section{(v) Contributions of Bio-Medical and Health Sciences}

The study was also analyzed the contributions of the subject category Bio-Medical and Health Sciences with its sub categories in e-PG Pathshala and the same is given in Table 8 below. It is observed that "Food and Nutrition" has contributed the maximum number of modules i.e. 602 (=23\%) followed by "Biophysics" and "Food Technology" with 17\% (=450 modules) and 13\% 
(=329 modules) respectively.

Table 8.Contribution of Bio-Medical and Health Sciences

\begin{tabular}{|l|l|l|l|l|}
\hline SN & Name of the Subject & $\begin{array}{l}\text { Total no of } \\
\text { Papers }\end{array}$ & $\begin{array}{l}\text { Total no of uploaded } \\
\text { modules }\end{array}$ & $\begin{array}{l}\text { Percentage } \\
(\%)\end{array}$ \\
\hline 1 & Food and Nutrition & 15 & 602 & 23 \\
\hline 2 & Biophysics & 14 & 450 & 17 \\
\hline 3 & Food Technology & 14 & 329 & 13 \\
\hline 4 & Biochemistry & 16 & 261 & 10 \\
\hline 5 & Biotechnology & 12 & 261 & 10 \\
\hline 6 & Pharmaceutical Science & 12 & 215 & 8 \\
\hline 7 & Zoology & 16 & 184 & 7 \\
\hline 8 & Botany & 7 & 176 & 7 \\
\hline 9 & $\begin{array}{l}\text { Social Medicine and Community } \\
\text { Health }\end{array}$ & 6 & 111 & 4 \\
\hline 10 & $\begin{array}{l}\text { Physical Education, Sports and } \\
\text { Health Education }\end{array}$ & 14 & 37 & 1 \\
\hline 11 & Bioinformatics & 2 & 1 & $\sim 0$ \\
\hline Total & $\mathbf{1 2 8}$ & $\mathbf{2 6 2 7}$ & $\mathbf{1 0 0}$ \\
\hline
\end{tabular}

\section{Statistical Analysis}

\section{Pearson's Correlation Test}

A correlation expresses the strength of linkage or co-occurrence between two variables. The most common measure of correlation in stats is the Pearson Product Moment Correlation (PPMC) which shows the linear relationship between two sets of data. The correlation coefficient between two continuous-level variables is called Pearson's $r$ or Pearson product-moment correlation coefficient which is represented typically as the letter $r$ and has a single value between -1 and +1 . This value measures the strength of the linkage (Laerd Statistics, 2020).

Significant correlations are marked with:

a) $\mathrm{p}<.05$ if the correlation is significant at alpha $=.05$ level.

b) $\mathrm{p}<.01$ if the correlation is significant at alpha $=.01$ level.

c) $\mathrm{p}<.001$ if the correlation is significant at alpha $=.001$ level. 
Table 9.Pearson's Correlation Matrix

\begin{tabular}{|l|l|l|l|l|l|}
\hline & Pearson's r & $\mathbf{p}$ & $\begin{array}{l}\text { Lower 95\% } \\
\text { CI }\end{array}$ & $\begin{array}{l}\text { Upper } \\
\text { 95\% CI }\end{array}$ & VS-MPR $\uparrow$ \\
\hline $\begin{array}{l}\text { No. of Paper- } \\
\text { No. of Uploaded } \\
\text { Module }\end{array}$ & $0.683 * * *$ & $1.908 \mathrm{e}-10$ & 0.530 & 0.793 & $8.614 \mathrm{e}+7$ \\
\hline$* \mathrm{p}<.05, * * \mathrm{p}<.01, * * * \mathrm{p}<.001$ & & & \\
\hline $\begin{array}{l}\dagger \text { Vovk-Sellke Maximum } p \text {-Ratio: Based on the } p \text {-value, the maximum possible odds in favor of } \mathrm{H}_{1} \\
\text { over } \mathrm{H}_{0} \text { equals } 1 /(-\mathrm{e} p \log (p) \text { for } p \leq .37 \text { (Sellke, Bayarri, \& Berger, 2001). }\end{array}$
\end{tabular}

A strong positive correlation was observed between No. of Paper-No. of Uploaded Module $\left(r_{p}=0.683, p=<.001\right)$. It is interesting to note that the nearer the value is to zero either positive or negative side), the weaker the relationship; and alternatively nearer the value is to +1 or -1 , the stronger the relationship in positive or negative side respectively. Table represents the brief calculation of the results of the correlations.

\section{$>$ Correlation plot}

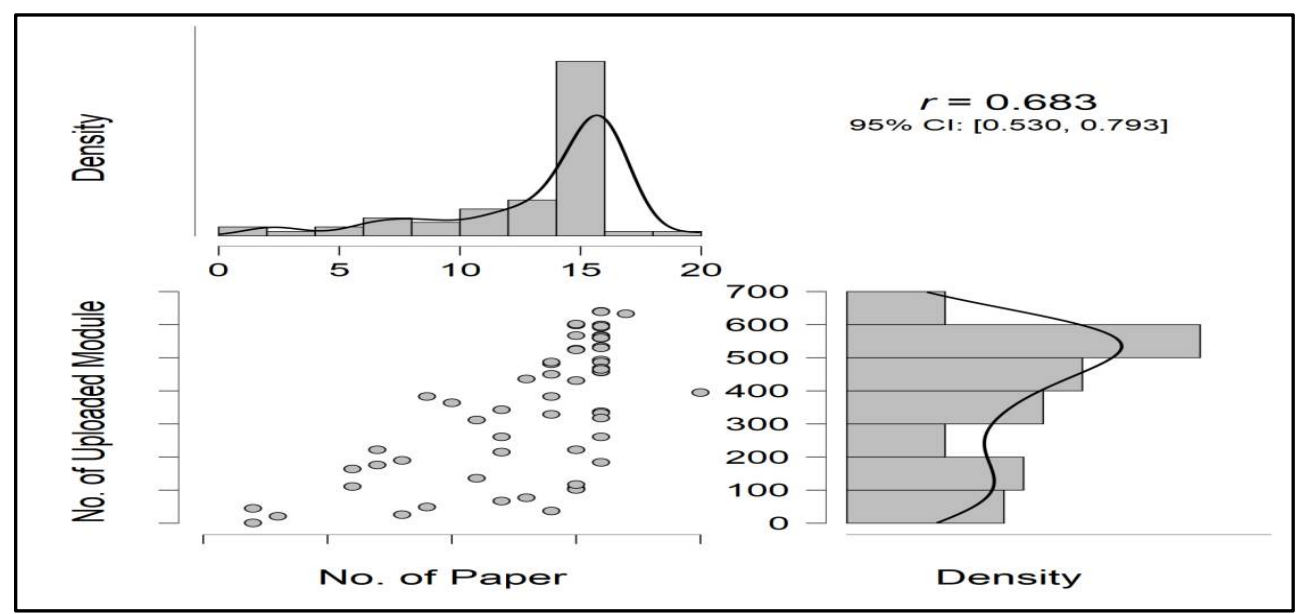

Figure 1.No. of Paper vs. No. of Uploaded Module

A Pearson correlation requires a linear relationship between each pair of variables. This hypothesis is violated if there is curvature among the scatter plot points within any pair of variables. Figure 1 above represents the scatter plot and the histogram of the correlation. It also indicates that there exists a linear correlation between the variables (i.e. No. of Paper-No. of Uploaded Module). The sharpness of the plot indicates the strength of the relation. A strong correlation displays by the sharp correlation plot of the rest two pairs of variables. The slope of the correlation plot determined the nature of the correlation (i.e. whether positive or negative). And in this case the slope indicates a strong correlation between the two variables.

\section{Findings \& Discussion}

This paper is based on the study of gathering, tabulating, arranging, assessing and analyzing the 
distribution of e-PG visitors concerning Geographical and Subject field. Following are some major findings evolved from the study,

Though it is mentioned in the description of e-PG Pathshala that it covers almost 70 individual subject field (Table 1) but in actual it provides data of 67 fields in its page, i.e. three fields are missing.

$>$ The subjects of e-PG Pathshala can be arranged according to two broad category, AHSS and STEMM; of which AHSS field occupied 62\% of total uploaded modules and rest $38 \%$ covered by STEMM field (Table 2).

$>$ The above mentioned broad categories further divided into five major subject category e.g. "Social Sciences", “Arts, Humanities and Languages", "Engineering, Technology and Management", "Physical and Basic Sciences" and "Bio-Medical and Health Sciences". Among these five fields first two covered under AHSS branch and the rest covered by STEMM field.

$>$ Among the 5 major subject category, "Social Sciences" contributed the maximum number of modules in e-PG Pathshala followed by "Arts, Humanities and Languages" and "Engineering, Technology and Management"(Table 3).

$>$ Under 5 major categories of the subject, there are a total of 67 individual subject discipline, 908 papers and 25174 modules (Table 3).

$>$ Among the subjects of Social Sciences, "Psychology" is the top contributor of modules in e-PG Pathshala whereas "Buddhist Studies" being the least one (Table 4).

$>$ In the case of Arts, Humanities and Languages field, "Home Science" and "Sanskrit (M.A.)" are the major contributor follwed by "Hindi". In this case "Chinese" being the least contributor contribute almost zero percent of the total (Table 5).

$>$ Among the contribution of Engineering, Technology and Management field to the e-content coverage of e-PG Pathshala, "Hotel \&amp; Tourism Management" contribute the maximum number of modules followed by "Computer Science", "Management", and "Human Resource Management" (Table 6).

"Statistics" contribute the maximum percentage of the total e-content coverage of Physical and Basic Sciences discipline followed by "Mathematics", "Chemistry", and "Jyotish-ganit" (Table 7).

$>$ The contributions of the subject category Bio-Medical and Health Sciences depends much on the "Food and Nutrition", "Biophysics" and "Food Technology" (Top 3 contributor) (Table 8).

$>$ Statistical analysis of the dataset of the variables, No. of Paper-No. of Uploaded Module results that, a strong positive correlation was observed between No. of Paper-No. of Uploaded Module $(\mathrm{rp}=0.683, \mathrm{p}=<.001)$ (Table 9) .

\section{Conclusion}

"Open Educational Resources are teaching, learning and research materials in any medium-digital or otherwise-that reside in the public domain or have been released under an 
open license that permits no-cost access, use, adaptation and redistribution by others with no or limited restrictions"(Hewlett Foundation, 2016). Two wide OER categories i.e. OCW and MOOCs play a crucial role in the higher education e-learning system. The Government of India has taken e-PG Pathshala as a new initiative to develop online learning by providing quality educational content to all learners in India through the National Mission on Education through Information and Communication and Technology (NMEICT). This well-known OCW platform has contributed more than 25,000 modules which cover both the subject branch i.e. STEMM and AHSS. Due to the awareness of the individual subject field and personal interest of the academician and researcher of a particular field, the module contribution of e-PG Pathshala is almost double for AHSS branch than STEMM. It is suggested that "Engineering, Technology and Management" and "Bio-Medical and Health Sciences" should contribute more modules for the benefit of Engineering and Medical students and learners. Again it can also be suggested that there should be a specific syllabus granted by UGC for each university and that should be followed in e-PG Pathshala e-content development. It can help the student community in India to acquire an equal quality of education which is free of any kind of discrimination.

\section{References}

1. e-PG Pathshala. (n.d.-a). About e-PG Pathshala. Retrieved June 4, 2020, from epgp.inflibnet.ac.in website: https://epgp.inflibnet.ac.in/\#.

2. e-PG Pathshala. (n.d.-b). e-PG Pathshala /Uploaded Course / Subjects. Retrieved June 4, 2020, from epgp.inflibnet.ac.in website: https://epgp.inflibnet.ac.in/.

3. Hajam, M. A. (2016). SWOT Analysis of e-PG Pathshala. Professional Journal of Library and Information Technology, 6(2). Retrieved from https://www.researchgate. net/publication/318108077_SWOT_ANALYSIS_OF_E-PG_PATHSHALA.

4. Hewlett Foundation. (2016, August 3). Open Educational Resources. Retrieved June 5, 2020, from https://hewlett.org/strategy/open-educational-resources/.

5. JASP Team (2019). JASP (Version 0.12.0.0) [Computer Software].

6. Laerd Statistics (2020). Pearson's product moment correlation. Statistical tutorials and software guides. Retrieved June 8, 2020, from https://statistics.laerd.com/statisticalguides/pearson-correlation-coefficient-statistical-guide.php.

7. Maharaj, N. G. (2018). A study on Role of e-PG Pathshala in the Development of e-learning. Knowledge Librarian, 5(1), 104-113. Retrieved from http://www.klibjlis. com/5.1.10.pdf.

8. Sellke, T., Bayarri, M. J., \& Berger, J. O. (2001). Calibration of $\rho$ Values for Testing Precise Null Hypotheses. The American Statistician, 55(1), 62-71. https://doi.org/10. 1198/000313001300339950.

9. Sze-yeng, F., \& Hussain, R. M. R. (2010). Self-directed learning in a socio constructivist learning environment. Procedia-Social and Behavioral Sciences, 9, 1913-1917. https://doi.org/10.1016/j.sbspro.2010.12.423. 